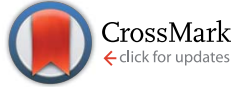

Cite this: RSC Adv., 2016, 6, 115092

Received 9th October 2016

DOI: $10.1039 / c 6 r a 24933 g$

www.rsc.org/advances
Accepted 30th November 2016

\section{Engineering-scale superlubricity of the fingerprint- like carbon films based on high power pulsed plasma enhanced chemical vapor deposition}

\begin{abstract}
Zhenbin Gong, $^{\text {ab }}$ Jing Shi, ${ }^{\text {ab }}$ Wei Ma, ${ }^{a}$ Bin Zhang ${ }^{a}$ and Junyan Zhang ${ }^{\star a}$
It has been a great challenge to achieve superlubricity on an engineering scale. In this study, macro superlubricity was realized by fingerprint-like carbon (FP-C:H) films that were prepared by a high power pulsed plasma enhanced chemical vapor deposition technique. The macro superlubricity occurred under a wide range of test conditions, with a super low friction coefficient of 0.0016 in dry air. The unique structure and properties of the graphene layers made it capable not only to lower the shearing stress but also efficiently achieve superlubricity, following reorganization mechanics. High-resolution transmission electron microscopy (HRTEM) and Raman spectroscopy revealed the nanostructure evolution of the wear debris. Surprisingly, a kind of multistorey graphene nanoparticles were generated in the wear debris and the humidity played an important role in the formation of these particles. Moreover, the nanostructures of these particles directly affected the friction coefficients at different humidity values. It can be demonstrated that the graphene nanoparticles were the major reason for the super lubrication of fingerprint-like carbon films, achieving incommensurate and rolling contacts. An engineering applicable method combined with the unique superlubricity properties of fingerprint-like carbon could offer an exciting opportunity to realize long-sought applications in vehicles, turbines, and manufacturing equipment.
\end{abstract}

\section{Introduction}

Both one-third of the world's primary energy consumption and four-fifth of the mechanical components failures are contributed to friction..$^{1,2}$ Therefore, friction reduction is particularly important for the environment and sustainable development. ${ }^{3}$ High requirements for superlubricity materials and technology have been put forward along with the development of vehicles, turbines, and manufacturing equipment. Although it is believed that superlubricity can save energy and extend the life of the moving parts, both technique and materials towards this have not yet been well-developed. In the past few decades, two kinds of materials showed an ultra-low friction coefficient and became interesting research topics in the field of superlubricity: one is two-dimensional materials, ${ }^{4-6}$ such as graphene, graphite, and graphite $/ \mathrm{C}_{60},{ }^{7-9}$ where the incommensurate contact can significantly reduce the friction and wear under specific conditions, and this unique friction state regarding the atomic lattice structures is called the "structural lubricity"; other one is the carbon based thin films, such as diamond like carbon and ultra nanocrystalline diamond films (friction

${ }^{a}$ State Key Laboratory of Solid Lubrication, Lanzhou Institute of Chemical Physics, Chinese Academy of Sciences, Lanzhou 730000, China. E-mail: zhangjunyan@licp. cas.cn

${ }^{b}$ University of Chinese Academy of Sciences, Beijing, 10049, China coefficient $\sim 0.001) .^{10,11}$ However, nearly all the experimental superlubricity has been obtained on microscope or under specific conditions (vacuum or dry conditions), which are obstacles towards its engineering applications since the superlubricity systems diminish most of its properties on the bulk scale or under atmosphere. ${ }^{12-14}$

Graphene exhibits the potential to achieve ultra-low friction, expected as an ideal candidate for the lubrication. ${ }^{15}$ Recently, macroscopic superlubricity was realized by graphene and nanodiamonds at the macroscale. The graphene sheets exhibited self-organization behavior at the sliding interface, forming nanoscrolls to create macroscopic scale superlubricity. ${ }^{16}$ A nanoscroll reduces the adhesion between the contact surfaces and achieves incommensurate contact, greatly reducing the friction and leading to structural superlubricity. However, in practical applications, thin films need to have a comprehensive performance, with good mechanics, stability, and high binding force. As a result, it remains an open question to design a solid surface at the nanoscale to sustain superlubricity at the engineering scales.

To bridge the gap between superlubricity and practical application, great efforts have been made to coat thin films on the component surfaces with various materials and structures. ${ }^{17}$ Vacuum coating is one of the most advanced technologies in the scientific research and industrial engineering, which makes it easy to achieve the comprehensive performance. ${ }^{1}$ Most 
importantly, adjusting the preparation process can control the nanostructure of thin films, which is the prerequisite for structural superlubricity. Generally, solid superlubricity mainly relies on the formation of incommensurate contact, which can be achieved by a variety of carbon nanostructures, such as graphite, ${ }^{7-9}$ graphene, ${ }^{12}$ nanodiamonds, ${ }^{16}$ and nanotubes. ${ }^{18,19}$ To date, it has been reported that thin films with novel nanostructure could be prepared with macro superlubricity properties through plasma vacuum deposition technology. ${ }^{20-22}$ However, extreme conditions or high energy preparation methods are necessary to synthesize these nanostructures; for example, graphene, ${ }^{23,24}$ nanotube, ${ }^{25,26}$ nanodiamonds, ${ }^{27}$ and fullerene ${ }^{28}$ can only be fabricated at high temperature, with high energy ions states, or with catalysts, and nanocrystallitesembedded amorphous carbon require methods such as modified arc techniques. ${ }^{29-33}$ Thus, the growth energy greatly impacts the formation of the nanostructured carbon. Moreover, for graphene, high growth energy can be reached via heating or high energy excitation and, therefore, involves high temperature (from $500{ }^{\circ} \mathrm{C}$ to more than $1000{ }^{\circ} \mathrm{C}$ ) or methods such as electron irradiation in the electron cyclotron resonance, mass selected ion beam deposition, arc-discharge, and microwave plasma enhanced chemical vapor deposition. ${ }^{23,34-41}$ This demonstrates that the high energy state can promote the formation of graphene-like sheets. High-power pulsed power supply, exciting ions (near arc discharge) with very high power densities and ion energy, ${ }^{\mathbf{4 2 , 4 3}}$ could be used to prepare the graphene-like nanostructures.

In this study, a type of fingerprint-like carbon films (FP-C:H) with curved graphene layers were deposited by a high power pulsed-plasma enhanced chemical vapor deposition technique (HiP-PECVD). It was proven that the films possessed stable superlubricity under a wide range of test conditions: counterpart balls from $\mathrm{Al}_{2} \mathrm{O}_{3}, \mathrm{Si}_{4} \mathrm{~N}_{3}$ to steel, load from $2 \mathrm{~N}$ to $20 \mathrm{~N}$ in dry air or with low humidity. It is believed that the superlubricity originates from the self-organization of graphene sheets to form graphene nanoparticles (GNPs), which offers an incommensurate and rolling contact. In addition, the simple method combined with the unique superlubricity properties offers an exciting opportunity to realize the long-sought applications in vehicles, turbines, and manufacturing equipment.

\section{Experimental}

\section{Film preparation}

Nanostructure carbon films were synthesized using HiP-PECVD. The base pressure of the deposition chamber was about $1 \times$ $10^{-4} \mathrm{~Pa}$. The samples were deposited on Si (100) in a flow of $\mathrm{CH}_{4}: \mathrm{H}_{2}=1: 1$ in a mixture of methane (99.99\%) and hydrogen (99.99\%) discharge, under work pressure at $30 \mathrm{~Pa}$. The power supply (JX-HPMS, JINXIN, CHINA) operated in a constant voltage mode under a negative voltage of $-2000 \mathrm{~V}$ with a peak current of $80 \mathrm{~A}$ (pulse frequency: $350 \mathrm{~Hz}$ ). The duty cycle was 0.05 , and accordingly, the maximum power was $160 \mathrm{~kW}$, whereas the average power was $8 \mathrm{~kW}$. The samples were mounted at a distance of $5 \mathrm{~cm}$ from the cathode.

\section{HRTEM samples preparation}

The high-resolution transmission electron microscope (HRTEM) samples were grown on freshly cleaved $\mathrm{NaCl}$ wafers with a thickness about $20 \mathrm{~nm}$. To avoid the metal contamination, before the TEM sample deposition, the substrate holder and vacuum chamber wall were coated by carbon films. The wear debris samples were prepared using a micro grid to polish the wear scar of the counterpart balls after friction testing.

\section{Thickness measurement}

The thickness of the film was obtained by a scanning electron microscope (JEOL JSM-6701F) from their cross-section samples.

\section{Structure characterizations}

Nanostructure of the thin films and wear debris were analyzed using a HRTEM Tecnai-G2 F30 (FEI, US) and Tecnai-G2 F20 (FEI, US), respectively. The graphene domain information was studied using atomic force microscopy (AFM Nanoscope Maltimode 8.0, Bruker Co. GER). In addition, further information regarding the structural arrangement was studied using a micro Raman spectrometer (LABRAM HR 800) at a wavelength of $532 \mathrm{~nm}(2.3 \mathrm{eV})$. Film composition and bonding information were analyzed by XPS (VG ESCALAB 210) using an Al-K $\alpha$ (1486.5 eV) X-ray radiation.

\section{Nanoindentation tests}

The mechanical properties of the FP-C:H films were measured by nanoindentation (Hysitron Ti-950) with a trigonal Berkovich diamond tip. The maximum indentation depth was controlled at about $50 \mathrm{~nm}$ (1/10 of the film thickness). The elastic recovery $R$ is defined as follows:

$$
R=\left(d_{\max }-d_{\text {res }}\right) / d_{\max } \times 100 \%
$$

where $d_{\text {max }}$ and $d_{\text {res }}$ are the maximum and residual displacements, respectively.

\section{Tribological characterization}

The tribological performances of the specimens were evaluated by the ball-on-disk reciprocating friction testing machine under dry, $10 \%, 20 \%, 30 \%, 40 \%$, and $50 \%$ relative humidity atmospheres. The counterpart balls were $\mathrm{Al}_{2} \mathrm{O}_{3}, \mathrm{ZrO}_{2}, \mathrm{Si}_{4} \mathrm{~N}_{3}$, and steel with a diameter of $5 \mathrm{~mm}$. The loading forces of the friction tests were $20 \mathrm{~N}, 15 \mathrm{~N}, 10 \mathrm{~N}, 5 \mathrm{~N}$, and $2 \mathrm{~N}$, respectively. The sliding diameter was $8 \mathrm{~mm}$, and the frequency was $10 \mathrm{~Hz}$.

\section{Results and discussion}

Fingerprint-like carbon (FP-C:H) with a thickness of about $700 \mathrm{~nm}$ were deposited on the silicon substrates. The nanostructure of the carbon films is shown in Fig. 1. The film has a very attractive and unique nanostructure (Fig. 1a), which can be described as distorted multistorey graphene arrangements in an amorphous body. The distance between two graphene sheets was about $0.34 \mathrm{~nm}$. Note that these patterns are very 

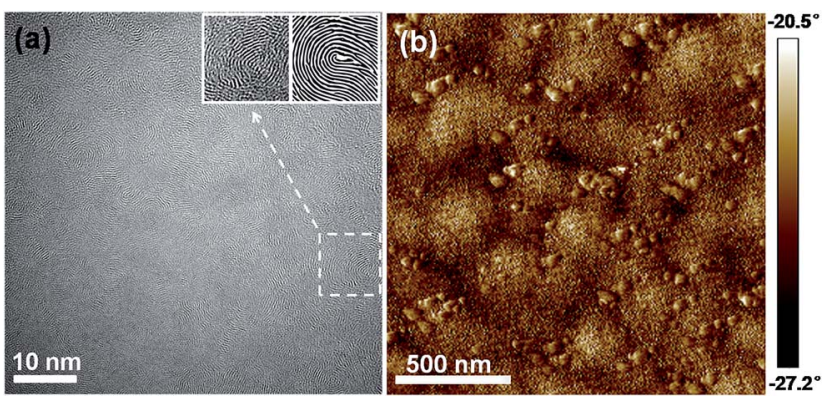

Fig. 1 (a) High-resolution transmission electron images of the FP-C:H films. Insets: carbon fingerprint and human fingerprint pattern. (b) An AFM phase image of the fingerprint-like carbon film deposited on a silicon wafer.

similar to those of a human fingerprint (inset picture), so it was named as fingerprint-like carbon (FP-C:H). Further, AFM phase imaging under tapping mode was used to study the graphene arrangement features and distributions. Since the phase image of AFM can distinguish the surface stiffness variations associated with Young's modulus changes, this can be used to identify the nanocluster domains in the film. ${ }^{44}$ Fig. 1 b shows an AFM phase image of a fingerprint-like carbon film deposited on a silicon wafer. It is obvious that the film had a special nanocomposite structure with graphene domains (soft) dispersed in an amorphous network (hard).

Raman spectroscopy, which can identify various carbon nanostructures, bonding structure, vibration mode and order degree, is a powerful tool to analyze the carbon-based materials. ${ }^{45}$ The FP-C:H films (Fig. 2a) show a typical feature spectrum of amorphous carbon from $1000 \mathrm{~cm}^{-1}$ to $1800 \mathrm{~cm}^{-1}$ at 633, 532, and $325 \mathrm{~nm}$ Raman exciting laser wavelengths. The main peak was decomposed into $\mathrm{D}$ and $\mathrm{G}$ bands by guess mode, where $0.62,0.79$, and 0.99 are the $I_{\mathrm{D}} / I_{\mathrm{G}}$ values for 633,532 , and $325 \mathrm{~nm}$ excitation wavelengths, respectively. The low values of $I_{\mathrm{D}} / I_{\mathrm{G}}$ indicate that the FP-C:H films had a high $\mathrm{sp}^{2}$ content. The size of the $\mathrm{sp}^{2}$ cluster $\left(L_{\mathrm{a}}\right)$ was calculated by the Tuinstra-Koenig relation as follows: ${ }^{46}$

$$
\frac{I_{\mathrm{D}}}{I_{\mathrm{G}}}=\frac{C\left(E_{\mathrm{laser}}\right)}{L_{\mathrm{a}}}
$$

where the value of the empirical constant $C\left(E_{\text {laser }}\right)$ depends on $E_{\text {laser. }}$ In the visible range $(390-780 \mathrm{~nm})$, the constant $C\left(E_{\text {laser }}\right)$ follows the following relationship: ${ }^{46}$

$$
C\left(E_{\text {laser }}\right)=\frac{560}{E_{\text {laser }}^{4}}
$$

Therefore, the equation can be simplified as follows: ${ }^{47}$

$$
L_{\mathrm{a}}(\mathrm{nm})=\frac{560}{E_{\text {laser }}{ }^{4}}\left(\frac{I_{\mathrm{D}}}{I_{\mathrm{G}}}\right)^{-1}=\left(2.4 \times 10^{-10}\right) \lambda_{\text {laser }}{ }^{4}\left(\frac{I_{\mathrm{D}}}{I_{\mathrm{G}}}\right)^{-1}
$$

where $E_{\text {laser }}(\mathrm{eV})$ is the laser excitation and $\lambda_{\text {laser }}(\mathrm{nm})$ is the wavelength value of the laser. For example, $L_{\mathrm{a}}$ at $532 \mathrm{~nm}$ excitation wavelength is about $24.7 \mathrm{~nm}$, which is much larger than that of the pure amorphous carbon $(1-2 \mathrm{~nm}){ }^{48-50}$ The large cluster size indicates that the fingerprint-like graphene clusters were present in the film. At the same time, a broad peak at around $3000 \mathrm{~cm}^{-1}$ in the $532 \mathrm{~nm}$ Raman spectrum indicates some additional features. Based on the reports for the Raman spectra of the defected multilayer graphene, ${ }^{51,52}$ the broad peak can be attributed to the $2 \mathrm{D}$ range of the defected graphene layers. These peaks broaden and merge due to a large number of defects, thereby, giving rise to the modulated $2 \mathrm{D}$ band in the wrinkled graphene. ${ }^{53}$ The $2 \mathrm{D}$ peak was decomposed into six peaks by Gauss calculation, as shown in Fig. $3 \mathrm{~b}$. The peaks positions were 2603, 2700, 2829, 2981, 3101, and $3190 \mathrm{~cm}^{-1}$, respectively. The bands at 2603 and $2700 \mathrm{~cm}^{-1}$ are the $2 \mathrm{D}_{1}$ and $2 \mathrm{D}_{2}$ bands of graphene, which are ascribed to the sub-bands of the $2 \mathrm{D}$ band, ${ }^{54}$ and $2829 \mathrm{~cm}^{-1}$ is the $\mathrm{D}^{*}$ band of the graphite structure. ${ }^{55}$ The 2981,3101 , and $3190 \mathrm{~cm}^{-1}$ bands are for the $\mathrm{D}+$ $\mathrm{D}^{*}, \mathrm{G}+\mathrm{D}^{*}$, and $2 \mathrm{D}^{\prime}$ of graphene, respectively. ${ }^{52,53}$

To further understand the nanostructure of FP-C:H, the elements composition and chemical structures were studied by XPS. Fig. $2 \mathrm{c}$ indicates the deconvolution of the XPS spectrum of the FP-C:H film. The $\mathrm{C}_{1 \mathrm{~s}}$ spectrum consists of four features of binding energy values obtained at 284.5, 285.2, 286.5, and $288.5 \mathrm{eV}$, corresponding to $\mathrm{sp}^{2}, \mathrm{sp}^{3}, \mathrm{C}-\mathrm{O}$, and $\mathrm{C}=\mathrm{O}$, and the full width at half maximum (FWHM) were 1.0, 1.0, 1.4, and $2.3 \mathrm{eV}$, respectively. ${ }^{56-58}$ The oxygen peaks were originated from the surface contamination when the FP-C:H film was exposed to air. ${ }^{59}$ Combining the results of HRTEM, Raman, and XPS, it can be concluded that graphene layers with a fingerprint-like pattern have been formed within the as-deposited carbon films.
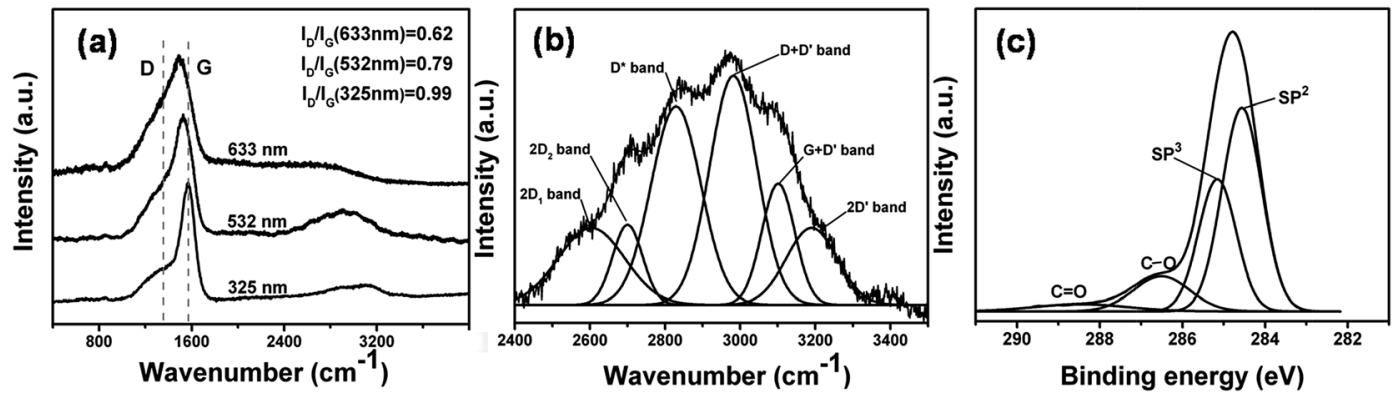

Fig. 2 (a) Raman spectra of the FP-C:H films with 633, 532, and $325 \mathrm{~nm}$ Raman excitation wavelengths. (b) The corresponding fitted Raman spectra of the FP-C:H films at $532 \mathrm{~nm}$ from 2400 to $3500 \mathrm{~cm}^{-1}$. (c) The deconvolution of the high-resolution XPS spectra of the $\mathrm{C}_{1 \mathrm{~s}}$ peak for FPC:H films. 

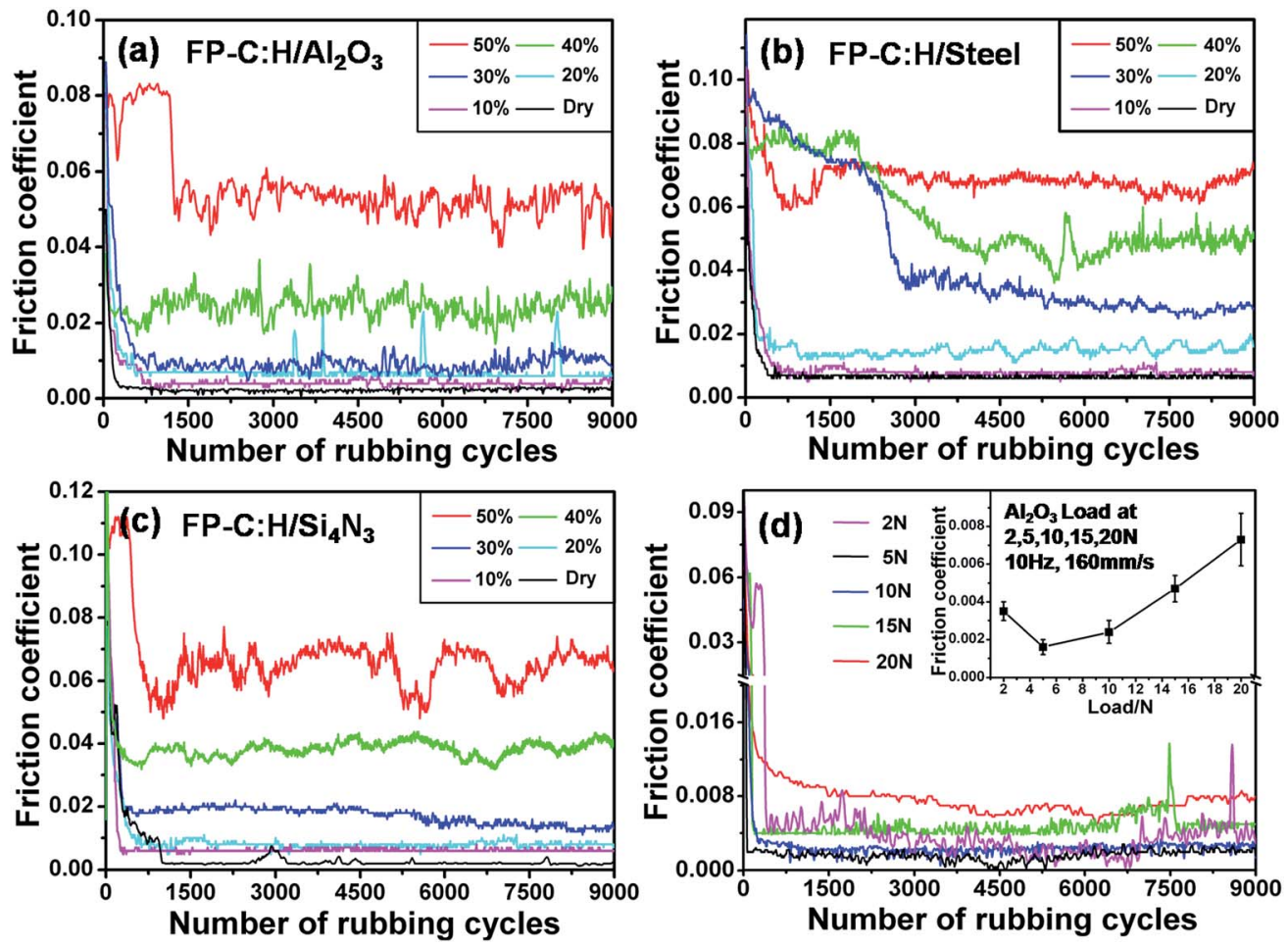

Fig. 3 (a), (b) and (c) The friction coefficient curves as a function of rubbing cycles at different humidity against $\mathrm{Al}_{2} \mathrm{O}_{3}, \mathrm{Si}_{4} \mathrm{~N}_{3}$, and steel ball, respectively. (d) Friction coefficient curves of the FP-C:H films in a dry air atmosphere under a load from $2 \mathrm{~N}$ to $20 \mathrm{~N}$, the inset shows the friction coefficient as a function of load.

The mechanical properties of the carbon thin film had a very significant effect on its friction performance and engineering applications. ${ }^{60}$ As listed in Table 1, the FP-C:H films exhibited a super-high elastic recovery $(R)$ of $84.6 \%$, which indicates a minimal plastic deformation during the indentation process. It also exhibited a high hardness of up to $22.8 \mathrm{GPa}$. Arguably, the three dimensions buckled and curved graphite layers gave rise to the high hardness and elastic recovery of the FP-C:H carbon films.

Moreover, the attractive macroscopic superlubricity properties have been observed for the FP-C:H carbon films. The friction behaviors were tested under dry, 10\%, 20\%, 30\%, 40\%, and $50 \%$ humidity atmospheres with different dual balls and loads (Fig. 3). The ambient temperature was about $20{ }^{\circ} \mathrm{C}$, and the sliding speed was about $160 \mathrm{~mm} \mathrm{~s}^{-1}$. An extremely low friction coefficient below 0.0016 was observed for the FP-C:H films sliding against the $\mathrm{Al}_{2} \mathrm{O}_{3}$ balls in a dry environment. Our experimental studies also confirmed that the stable superlubricity regime occurred under a wide range of test conditions: counterpart balls changed from $\mathrm{Al}_{2} \mathrm{O}_{3}, \mathrm{Si}_{4} \mathrm{~N}_{3}$ to steel, load from
$2 \mathrm{~N}$ to $20 \mathrm{~N}$, and atmosphere from dry air to low-humidity air. For example, the $\mathrm{Al}_{2} \mathrm{O}_{3} / \mathrm{FP}-\mathrm{C}: \mathrm{H}$ friction couple had a super low friction coefficient under low-humidity air (friction coefficient was less than 0.01 when the humidity was below $30 \%$ ). At the same time, macroscale superlubricity could be achieved under a load ranging from $2 \mathrm{~N}$ to $20 \mathrm{~N}$. From the friction curves (Fig. 3a-c), it was found that for all the friction pairs, an increase in the humidity led to an increase in the friction. The friction mechanism is very important for understanding the superlubricity properties of the thin films. Previous studies have shown that superlubricity can be achieved by the hydrogenated and sulfur-doped hydrogenated carbon films, where the ultralow friction originates from the passivation species in the test environment, such as $\mathrm{H}$ or $\mathrm{S}-\mathrm{H}$ bonding. ${ }^{\mathbf{6 1 , 6 2}}$ However, for FP$\mathrm{C}: \mathrm{H}$ films, there is no highly passive $\mathrm{H}$ bonds due to the oxygen enrichment ${ }^{\mathbf{4 1}}$ and though $\mathrm{O}-\mathrm{H}$ has a higher bond energy than that of $\mathrm{S}-\mathrm{H}^{63}$ because the oxidation of carbon is preferred. Therefore, it seems reasonable to surmise that the special nanostructure in the FP-C:H films greatly enhanced the tribological properties.

Table 1 Mechanical properties of the FP-C:H films

\begin{tabular}{lllll}
\hline & Indentation depth, $\mathrm{nm}$ & Hardness, GPa & Elastic module, GPa & Elastic recovery, \% \\
\hline Test & $45-52$ & $20.2-24.6$ & $140.1-162.2$ & $82-87$ \\
Average & 49 & 22.8 & 154.2 & 84.6
\end{tabular}


To explore the ultra-low friction mechanism of the FP-C:H films, the wear debris and wear scar were monitored by Raman spectroscopy. The Raman spectra were obtained at different positions at one time for each sample, as shown in Fig. 4a. The results (Fig. 4b) indicated that the structural transformation of the freshly exposed surface was not obvious; however, the wear debris showed significant structural changes reflected by the Raman spectra red shift, and the area ratio of $I_{2 \mathrm{D}} / I_{\mathrm{D}+\mathrm{G}}+I_{2 \mathrm{D}}$ increased with a decrease in the humidity. According to the abovementioned discussion, the area of $2 \mathrm{D}$ range can be regarded as the contents of graphene structure. Fig. 4c shows the friction coefficients and 2D range proportion as a function of humidity. The results of Raman spectroscopy demonstrated that the wear scar had a similar structure as the intrinsic films, whereas the interface structure evolution and bonding recombination mainly occurred in the wear debris. For the same friction experiment, the more dry the environment, the more its conducive for the formation and accumulation of graphene structure.

The FP-C:H films suffered from significant wear during sliding, however, the structural changes occurred mainly in the wear debris (Fig. 4a and b). It was found that the superlubricity could be achieved under a wide range of test conditions, but was influenced by the related humidity (HR). Therefore, an understanding of the humidity-controlled wear debris evolution could further explore the underlying mechanism of the superlubricity. To study the nanostructure of the wear debris on the $\mathrm{Al}_{2} \mathrm{O}_{3}$ balls under different humidity values, a more detailed analysis of the wear debris formed during the superlubricity regime in dry air was carried out by HRTEM. Fig. 5 shows the nanostructure transformation of the wear debris. Surprisingly, multilayer graphene nanoparticles (GNPs) were observed in the wear debris. This unique phenomenon is likely to be a key to understanding the origin of an ultra-low friction coefficient of the FP-C:H films. In dry environments, the GNPs indicated a perfect spherical shell structure with fewer defects (Fig. 5a). Under the $10 \%$ relative humidity (Fig. 5b), the multilayer shell structure could still be maintained, but with more defects. When the humidity was increased to $20 \%$ (Fig. 5c), the laminated shell structure distortion and lamella spacing distribution became wider and was mixed with an amorphous structure (Fig. 5d). Under 30\% humidity, the shell structure of the GNPs was broken, the defects increased, and an amorphous structure was introduced. At $40 \%$ humidity, the multilayer shell structure disappeared in the wear debris and only short curved graphene sheets could be observed (Fig. 5e). When the humidity was increased to $50 \%$, the GNPs showed a typical amorphous structure with short-range fingerprint-like graphene sheets (Fig. 5f). The wear debris was composed of spherical nanoparticles, which originated from the multilayer graphene. The decrease in the particle radius (Fig. 5, inset table) was accompanied by the destruction of the shell structure, which increased the resistance of friction. The graphitic layers with a lamellar spacing of $0.32-0.40 \mathrm{~nm}$ were not perfectly conformal and did not have a continuous structure. Obviously, the nanostructure transformation of wear debris along with humidity was in well accordance with the friction coefficients. By analyzing the Raman spectra and HRTEM images, it was determined that the superlubricity of the FP-C:H films originated from the evolution of GNPs.

Based on the results of tribology, HRTEM, and Raman, it was concluded that under a certain contact pressure, humidity controls the formation of GNPs, which further influence the friction behavior. In other words, the superlubricity of the FP$\mathrm{C}: \mathrm{H}$ films is related to the formation of GNPs at the
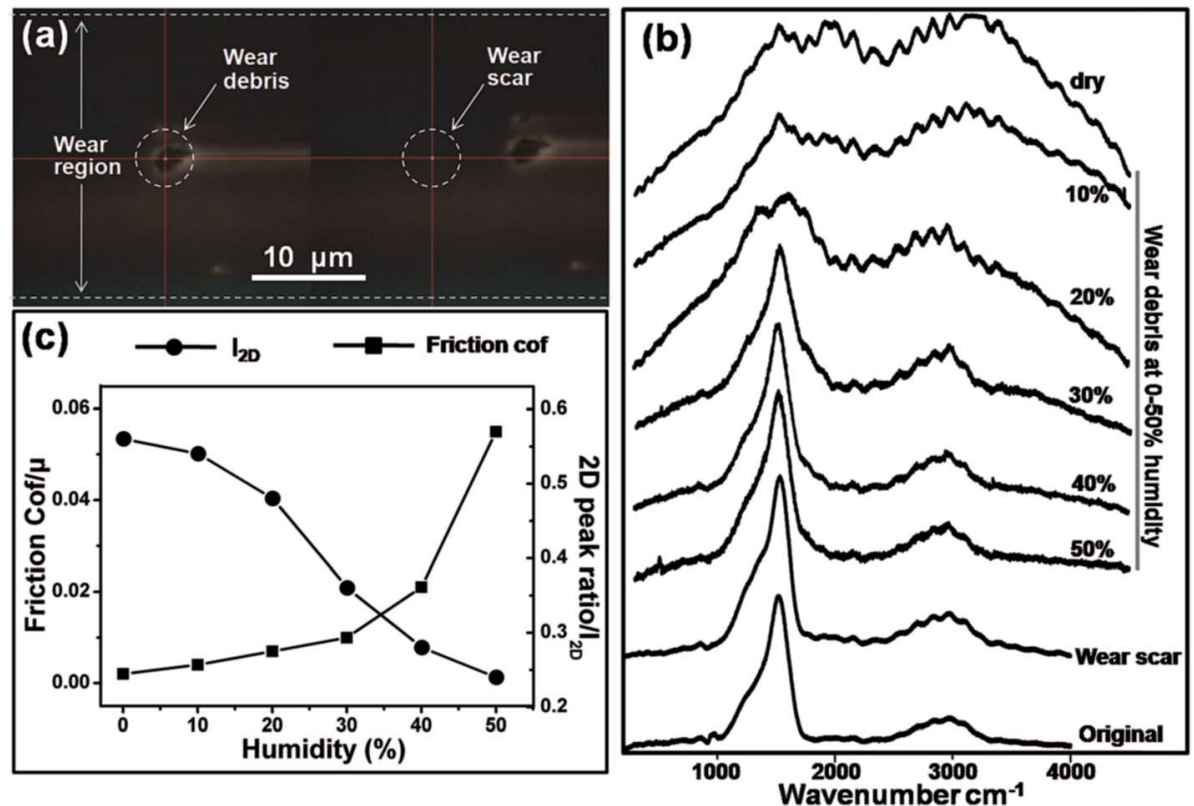

Fig. 4 (a) Microscopic images of the wear debris and wear scar. (b) Raman spectra of the original films, wear scar, and the wear debris (under dry, $10 \%, 20 \%, 30 \%, 40 \%$, and 50\% related humidity, respectively). (c) Friction coefficient and 2D peak as a function of humidity. 

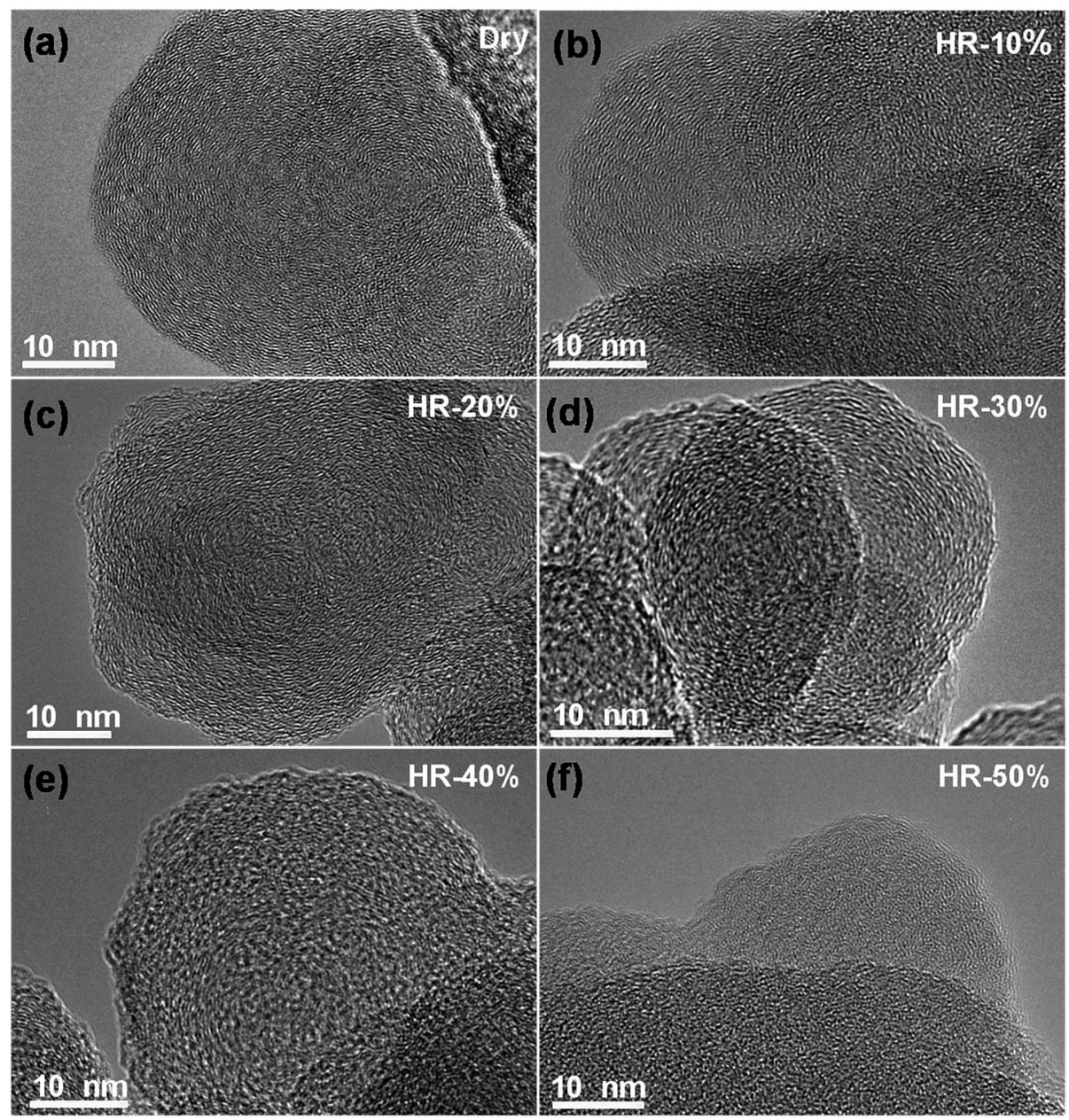

\begin{tabular}{ccccccc}
\hline Humidity & dry & $10 \%$ & $20 \%$ & $30 \%$ & $40 \%$ & $50 \%$ \\
\hline Average diameter(nm) & 41 & 38 & 37 & 34 & 33 & 30 \\
\hline
\end{tabular}

Fig. 5 HRTEM images of the wear debris: (a), (b), (c), (d), (e) and (f) under $0 \%, 10 \%, 20 \%, 30 \%, 40 \%$, and $50 \%$ humidity, respectively, at $10 \mathrm{~N}$ and $10 \mathrm{~Hz}$. Inset table, the average diameter of the graphene nanoparticles at different humidity values.

counterparts interfaces, thus, revealing that the formation mechanism can help us to better understand the superlubricity.

In the present study, we proposed that the formation mechanism of GNPs is the self-organization of graphene sheets, which can be divided into two steps, nucleation and growth. The nucleation of the GNPs core is similar to the reaction pathway for the transformation of graphene-to-fullerene since the molecular cage of fullerene is more stable than that of graphene. ${ }^{63-65}$ However, the driving force of the process is not high temperature but the friction shear force. A possible nucleation and growth mode is given in Fig. 6 . The nucleation process can be divided into four stages: (1) at the initial stage, the dual surface and the film have strong coupling, resulting in a strong wear and a large number of wear debris. The graphene layers (Fig. 6a) peeled off from the bulk body and directly contacted with the dual surface (Fig. 6f); (2) subsequently, these graphene sheets (Fig. 6b) (1) are folded and coiled under the shear stress (Fig. 6g); (3) with the development of a friction process, these short-range graphene fragments are coiled to form a cage-like structure under the action of periodic shearing forces (Fig. 6h); and (4) after more friction cycles, the carbon cage-like structure becomes more regular (Fig. 6i), where the positions 2 and 3 (Fig. 6c) mark a monolayer and a double layer, respectively. The single wall carbon cage diameter was about $0.7 \mathrm{~nm}$, which has a radius similar to that of $\mathrm{C}_{60}(0.71 \mathrm{~nm})$.

The growth mechanism can be inferred from the HRTEM images of the wear debris. The defected graphene layers (soft) are easy to package a fullerene core (hard), which is similar to the mechanism reported by A. V. Sumant et al. ${ }^{16}$ The growth model of the GNPs was similar to that of the snowball effect. When the friction process tends to reach a balance, the thermodynamic non-equilibrium state of the FP-C:H films tends to reach an equilibrium state. A large class of GNPs could be formed after 3000 friction cycles (Fig. 6d). Few GNPs layers (position 4) could be found on the edge of a big particle, which can be seen as an evidence for this form of nucleation and 

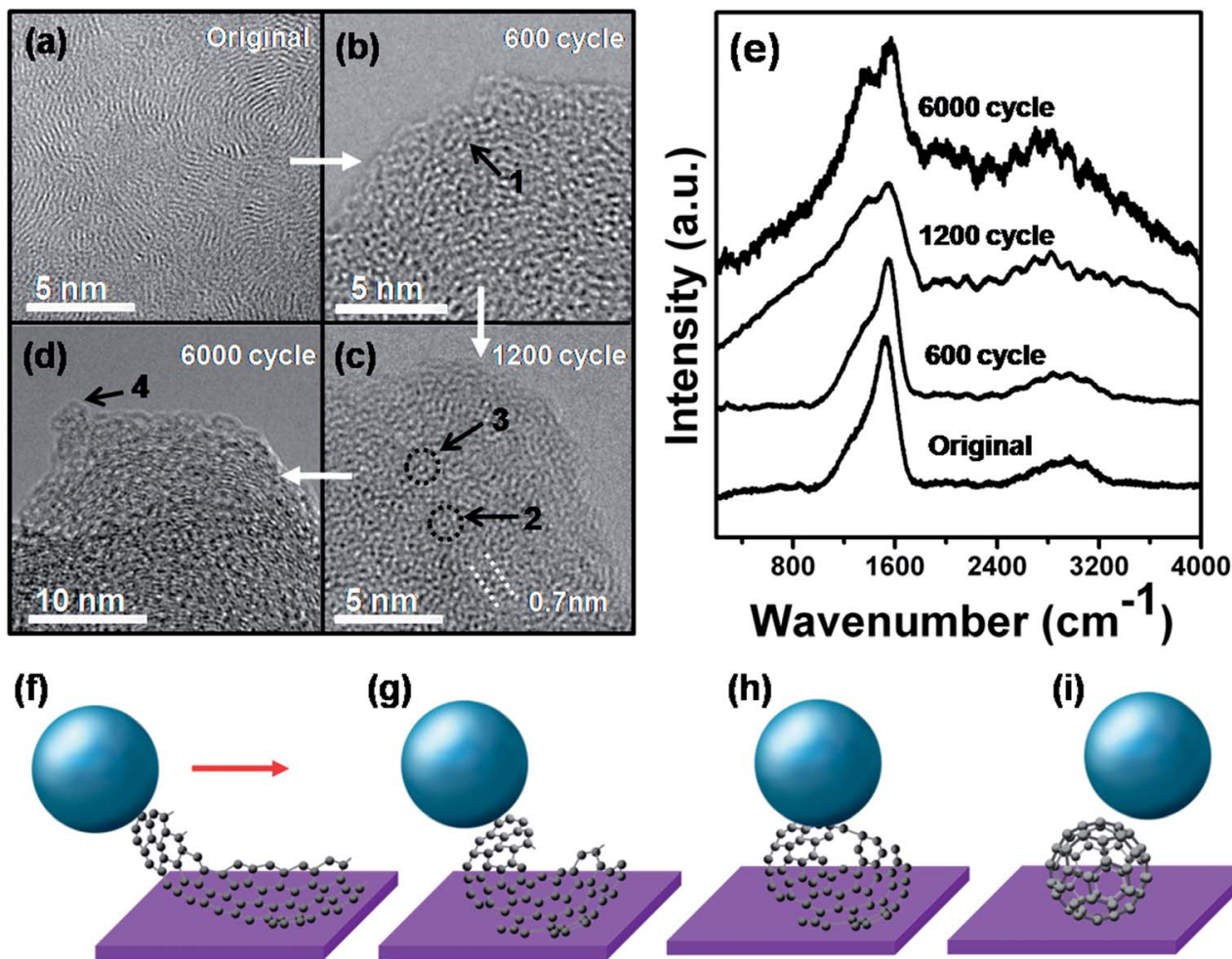

(g)

(j)

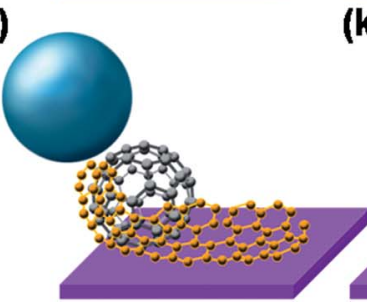

(k)

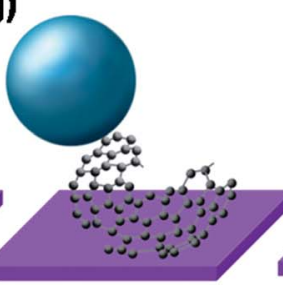

(h)
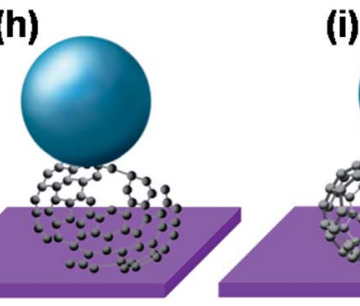

(i)

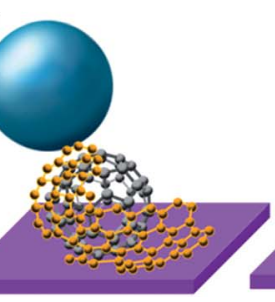

(I)
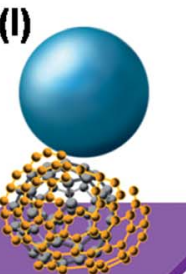

(m)

(m)

Fig. 6 (a) HRTEM images of the original FP-C:H films. (b)-(d) Wear debris of 600, 1200, and 6000 friction cycles, at $10 \mathrm{~N}$ and $10 \mathrm{~Hz}$. (e) Raman spectra of the original films and wear debris of 600,1200 , and 6000 friction cycles, respectively. (f) $-(\mathrm{m})$ Schematic of the nucleation and growth model for GNPs.

growth pattern. Raman spectra of the original films and wear debris of 600,1200 , and 6000 friction cycles also confirmed this growth model (Fig. 6e) since the $I_{2 \mathrm{D}} / I_{\mathrm{D}+\mathrm{G}}+I_{2 \mathrm{D}}$ values increased accordingly. Fig. $6 \mathrm{j}-\mathrm{m}$ are a possible growth model. Due to the spontaneous reduction of the surface energy, the graphene sheets tended to wrap around the carbon cage core to reduce the surface area (Fig. 6j and k). Under the effect of shear stress, the bonding recombination occurred at the interface, which finally leads to the formation of multilayer GNPs (Fig. 61 and m).

Theoretical study of the graphene-fullerene transformation confirmed that the formation of defects at the edge of graphene is the crucial step. ${ }^{63}$ To understand why water molecules can control the self assembly process, its molecular structure on the graphene edges should be further explored. The water molecules are made up of oxygen and hydrogen, with respective electro negativities of 3.44 and 2.20 (Fig. 7a). The dipoles from each of the two bonds (black arrows) add together to make the overall molecule polar (gray arrow) with a dipole moment of magnitude $p=6.20 \times 10^{-30} \mathrm{C} \mathrm{m} \cdot{ }^{66}$ Graphene is always found to be p-doped as a result of $\mathrm{H}_{2} \mathrm{O}$ adsorption from air. ${ }^{67}$ Water molecules exhibit higher activation energies than those of the non-polar adsorbates $\left(\mathrm{O}_{2}, \mathrm{~N}_{2}\right.$, and $\left.\mathrm{Ar}\right)$ and tend to form hydrogen bonds, which can be attributed to stronger adsorbateadsorbate interactions. ${ }^{68}$ Under dry environments, unsaturated dangling bonds of graphene had a high reaction activity, and the hybridization was easy to occur on the edge of graphene fragments (Fig. 7b). When water molecules are involved in the friction process, some of the dangling bonds are saturated by the water molecules, which blocks the hybridization of the graphene fragment (Fig. 7c). Under high humidity conditions (Fig. 7d), the water molecules almost saturate the dangling bonds of the lamellar surfaces, which limits the nucleation and growth of GNPs.

It is expected that the multistorey spherical nanostructures would provide wonderful tribological properties compared to those of the amorphous form of the solid lubricants. ${ }^{16,18}$ Combined with the HRTEM results, it is speculated that the GNPs in the debris could constitute an incommensurate contact surface because the number of atoms in the GNPs are not the same as in the FP-C:H carbon surfaces. Furthermore, it is known that the coefficients of rolling friction are generally $10^{2}$ to $10^{3}$ times lower than those of the sliding friction for the 

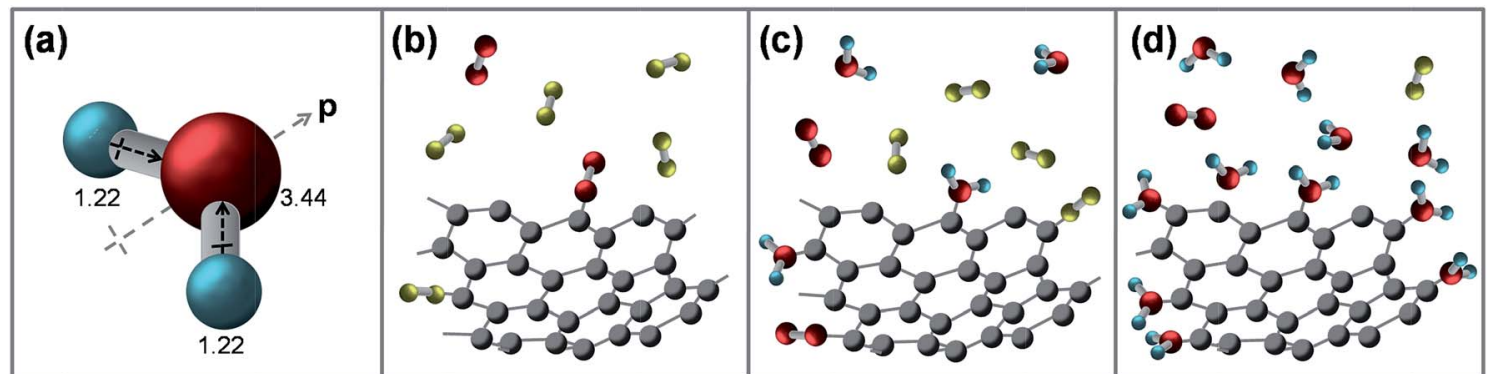

Fig. 7 The structure of water molecules: (a) molecular adsorption models of the graphene fragments at different humidity values: (b) dry atmosphere, (c) low humidity, and (d) high humidity.

corresponding materials. ${ }^{69}$ This is obvious because most of the nanoparticles obtained through the friction process have a regular spherical shape. In addition, these particles have a chemically inert surface, which reduces the couple of the dual interface. Actually, even under high humidity values up to $30 \%$, wear debris can only form a multilayer structure, and the low shear-strength properties can be maintained during the tribological testing. This is due to the creep deformation of the curved layered structure in the wear debris. The frictionless property disappears only when the wear debris tends to be amorphous (humidity reaches $40 \%$ or more).

\section{Conclusions}

In summary, FP-C:H films were fabricated by the HiP-PECVD technique at room temperature. The films have fingerprintlike structures, which endow high hardness, high elastic recovery, and an ultra-low friction coefficient $(\mu=0.0016)$ both in dry atmosphere and low humidity. The FP-C:H films could meet the requirements of the engineering scales for superlubricity, such as load, humidity, and dual materials, which overcome the shortcoming of the existing technology that superlubricity can only be acquired at microscale or under special conditions (vacuum or dry atmosphere). At the same time, the mature method (PECVD) reduces the cost and technical difficulty in the industry applications and enhances the stability and reliability of this superlubricity technology. For friction mechanism, it is believed that the superlubricity originates from the self-organized GNPs in the wear debris, with lower shear-strength properties, and offers incommensurate and rolling contact. The stress-induced GNPs formation by the interface is the possible reason for the existence of superlubricity in the dry and low humidity conditions. The FP-C:H films with superlubricity properties obtained under various conditions and the mature PECVD technology could promote the application of the superlubricity technology.

\section{Acknowledgements}

The authors are grateful to the National Key Basic Research and Development (973) Program of China (Grant No. 2013CB632300), the National Natural Science Foundation of
China (Grant No. 51275508, 51305434), and the CAS "Light of West China” Program.

\section{References}

1 A. Z. Szeri, Tribology: Friction, Lubrication, and Wear, Hemisphere, New York, 1980.

2 J. Li, C. Zhang, M. Deng and J. Luo, RSC Adv., 2015, 5, 3086130868.

3 R. Quadrelli and S. Peterson, Energy Policy, 2007, 35, 59385952.

4 K. M. Liechti, Science, 2015, 348, 632-633.

5 J. Yuan and K. M. Liew, RSC Adv., 2014, 4, 45425-45432.

6 O. Hod, Phys. Rev. B: Condens. Matter Mater. Phys., 2012, 86, 075444 .

7 M. Dienwiebel, G. S. Verhoeven, N. Pradeep, J. W. Frenken, J. A. Heimberg and H. W. Zandbergen, Phys. Rev. Lett., 2004, 92, 126101.

8 Z. Liu, J. Yang, F. Grey, Z. Liu, Y. Liu, Y. Wang, Y. Yang, Y. Cheng and Q. Zheng, Phys. Rev. Lett., 2012, 108, 205503.

9 K. Miura, S. Kamiya and N. Sasaki, Phys. Rev. Lett., 2003, 90, 055509.

10 A. Erdemir, O. L. Eryilmaz and G. Fenske, J. Vac. Sci. Technol., A, 2000, 18, 1987-1992.

11 A. R. Konicek, D. S. Grierson, P. U. P. A. Gilbert, W. G. Sawyer, A. V. Sumant and R. W. Carpick, Phys. Rev. Lett., 2008, 100, 235502.

12 J. A. Ruan and B. Bhushan, J. Appl. Phys., 1994, 76, 81178120.

13 J. Xiao, L. Zhang, K. Zhou, J. Li, X. Xie and Z. Li, Carbon, 2013, 65, 53-62.

14 K. Miura, S. Kamiya and N. Sasaki, Phys. Rev. Lett., 2003, 90, 055509.

15 A. Smolyanitsky, RSC Adv., 2015, 5, 29179-29184.

16 D. Berman, S. A. Deshmukh, S. K. Sankaranarayanan, A. Erdemir and A. V. Sumant, Science, 2015, 348, 1118-1122.

17 D. M. Mattox and V. H. Mattox, Vacuum coating technology, William Andrew Publishing, New York, 2003.

18 J. Cumings and A. Zettl, Science, 2000, 289, 602-604.

19 A. Kis, K. Jensen, S. Aloni, W. Mickelson and A. Zettl, Phys. Rev. Lett., 2006, 97, 025501. 
20 Q. Zeng, O. Eryilmaz and A. Erdemir, RSC Adv., 2015, 5, 93147-93154.

21 X. Liu, J. Yang, J. Hao, J. Zheng, Q. Gong and W. Liu, Adv. Mater., 2012, 24, 4614-4617.

22 B. Deepthi and H. C. Barshilia, Aerosp. Mater. Handb., 2012, p. 359.

23 Z. Wang, Z. Liu, M. A. Monne, S. Wang, Q. Yu and M. Y. Chen, RSC Adv., 2016, 6, 24865-24870.

24 X. H. Lin and J. G. Gai, RSC Adv., 2016, 6, 17818-17844.

25 G. Chen, Y. Seki, H. Kimura, S. Sakurai, M. Yumura, K. Hata and D. N. Futaba, Sci. Rep., 2014, 4, 3804.

26 N. M. Briggs and S. P. Crossley, RSC Adv., 2015, 5, 8394583952.

27 K. Teii, IEEE Trans. Plasma Sci., 2014, 42, 3862-3869.

28 G. N. Churilov, P. V. Novikov, V. E. Tarabanko, V. A. Lopatin, N. G. Vnukova and N. V. Bulina, Carbon, 2002, 40, 891-896.

29 O. S. Panwar, R. K. Tripathi, A. K. Srivastava, M. Kumar and S. Kumar, Diamond Relat. Mater., 2012, 25, 63-72.

30 O. S. Panwar, A. K. Srivastava, S. Kumar, R. K. Tripathi, M. Kumar and S. Singh, Surf. Coat. Technol., 2011, 206, 155-164.

31 R. K. Tripathi, O. S. Panwar, A. K. Srivastava, I. Rawal and S. Chockalingam, Talanta, 2014, 125, 276-283.

32 O. S. Panwar, S. Kumar, A. K. Srivastava, A. Chouksey, R. K. Tripathi and A. Basu, Mater. Chem. Phys., 2012, 132, 659-666.

33 R. K. Tripathi, O. Panwar, A. K. Srivastava, M. Kumar and S. Chockalingam, J. Nanosci., 2013, 401710.

34 C. Wang, D. Diao, X. Fan and C. Chen, Appl. Phys. Lett., 2012, 100, 231909.

35 E. H. T. Teo, J. Kulik, Y. Kauffmann, R. Kalish and Y. Lifshitz, Appl. Phys. Lett., 2011, 98, 123104.

36 K. S. Subrahmanyam, L. S. Panchakarla, A. Govindaraj and C. N. R. Rao, J. Phys. Chem. C, 2009, 113, 4257-4259.

37 O. S. Panwar, A. K. Kesarwani, S. R. Dhakate, B. P. Singh, R. K. Rakshit, A. Bisht and S. Chockalingam, J. Vac. Sci. Technol., B: Nanotechnol. Microelectron.: Mater., Process., Meas., Phenom., 2013, 31, 040602.

38 A. K. Kesarwani, O. S. Panwar, S. Chockalingam, A. Bisht, S. R. Dhakate, B. P. Singh and R. K. Rakshit, Sci. Adv. Mater., 2014, 6, 2124-2133.

39 A. K. Kesarwani, O. S. Panwar, S. R. Dhakate, R. K. Rakshit, V. N. Singh, A. Bisht and A. Kumar, J. Vac. Sci. Technol., A, 2016, 34, 021504.

40 A. Bisht, S. Chockalingam, O. S. Panwar, A. K. Kesarwani, B. P. Singh and V. N. Singh, Sci. Adv. Mater., 2015, 7, 14241434.

41 S. Chockalingam, A. Bisht, O. S. Panwar, A. K. Kesarwani, B. P. Singh, J. Chand and V. N. Singh, Mater. Chem. Phys., 2015, 156, 38-46.

42 V. Kouznetsov, K. Macak, J. M Schneider, U. Helmersson and I. Petrov, Surf. Coat. Technol., 1999, 122, 290-293.

43 D. Lundin and H. Pedersen, Phys. Procedia, 2013, 46, 3-11.
44 Y. Wang, D. C. Alsmeyer and R. L. McCreery, Chem. Mater., 1990, 2, 557-563.

45 S. N. Magonov, V. Elings and M. H. Whangbo, Surf. Sci., 1997, 375, 385-391.

46 L. G. Cançado, K. Takai, T. Enoki, M. Endo, Y. A. Kim, H. Mizusaki, N. L. Speziali, A. Jorio and M. A. Pimenta, Carbon, 2008, 46, 272-275.

47 M. S. Dresselhaus, A. Jorio, A. G. Souza Filho and R. Saito, Philos. Trans. R. Soc., A, 2010, 368, 5355-5377.

48 J. Schwan, S. Ulrich, V. Batori, H. Ehrhardt and S. R. P. Silva, J. Appl. Phys., 1996, 80, 440-447.

49 H. Ehrhardt, R. Kleber, A. Kru, W. Dworschak, K. Jung, I. Mu and H. Metz, Diamond Relat. Mater., 1992, 1, 316-320.

50 R. Kleber, K. Jung, H. Ehrhardt, I. Mühling, K. Breuer, H. Metz and F. Engelke, Thin Solid Films, 1991, 205, 274-278.

51 M. Mowry, D. Palaniuk, C. C. Luhrs and S. Osswald, RSC Adv., 2013, 3, 21763-21775.

52 E. M. Ferreira, M. V. Moutinho, F. Stavale, M. M. Lucchese, R. B. Capaz, C. A. Achete and A. Jorio, Phys. Rev. B: Condens. Matter Mater. Phys., 2010, 82, 125429.

53 L. M. Malard, M. H. D. Guimaraes, D. L. Mafra and A. Jorio, Phys. Rev. B: Condens. Matter Mater. Phys., 2009, 79, 125426.

54 C. W. Huang, B. J. Lin, S. Y. Juang, F. Y. Shih, W. H. Wang, C. Y. Liu and H. C. Chui, RSC Adv., 2014, 4, 51067-51071.

55 Q. Wu, Y. Shen, Q. Wang, F. Gu, M. Cao and L. Wang, in Eighth International Conference on Thin Film Physics and Applications, 2013, 90681T-90681T.

56 J. Filik, P. W. May, S. R. J. Pearce, R. K. Wild and K. R. Hallam, Diamond Relat. Mater., 2003, 12, 974-978.

57 J. L. Hueso, J. P. Espinós, A. Caballero, J. Cotrino and A. R. González-Elipe, Carbon, 2007, 45, 89-96.

58 W. H. Lee, J. G. Lee and P. J. Reucroft, Appl. Surf. Sci., 2001, 171, 136-142.

59 O. L. Eryilmaz and A. Erdemir, Tribol. Lett., 2007, 28, 241249.

60 A. H. Lettington, Carbon, 1998, 36, 555-560.

61 A. Erdemir, J. Fontaine and C. Donnet, Tribology of DiamondLike Carbon Films, Springer, US, 2008, pp. 237-262.

62 C. A. Freyman, Y. F. Chen and Y. W. Chung, Surf. Coat. Technol., 2006, 201, 164-167.

63 A. Chuvilin, U. Kaiser, E. Bichoutskaia, N. A. Besley and A. N. Khlobystov, Nat. Chem., 2010, 2, 450-453.

64 Y. E. Lozovik and A. M. Popov, Phys.-Usp., 1997, 167, 751774.

65 J. Y. Huang, F. Ding, K. Jiao and B. I. Yakobson, Phys. Rev. Lett., 2007, 99, 175503.

66 L. Pauling, The nature of the chemical bond and the structure of molecules and crystals: an introduction to modern structural chemistry, Cornell university press, 1960.

67 L. Kong, A. Enders, T. S. Rahman and P. A. Dowben, J. Phys.: Condens. Matter, 2014, 26, 443001.

68 H. Ulbricht, R. Zacharia, N. Cindir and T. Hertel, Carbon, 2006, 44, 2931-2942.

69 O. M. Braun, Phys. Rev. Lett., 2005, 95, 126104. 